\title{
Effectiveness of teaching cognitive-behavioral techniques on locus of control in hemodialysis patients
}

\author{
Mohammad Mehrtak ${ }^{1}$, Shahram Habibzadeh², Esmaeil Farzaneh ${ }^{3}$, Abdollah Rjaei-Khiavi ${ }^{4}$
}

${ }^{1}$ Ph.D. Assistant Professor, Department of Health Information Management, Faculty of Paramedical Sciences, Ardabil University of Medical Sciences, Ardabil, Iran

${ }^{2}$ M.D. Associate Professor, Department of Infectious Diseases, Faculty of Medicine, Ardabil University of Medical Sciences, Ardabil, Iran

${ }^{3}$ M.D. Associate Professor, Department of Forensic Medicine and Toxicology, Faculty of Medicine, Ardabil University of Medical Sciences, Ardabil, Iran

${ }^{4}$ MSc. Department of Psychology, Faculty of Human Sciences, Azad University, Ardabil, Iran

\section{Type of article: Original}

\begin{abstract}
Background: Many of the cognitive behavioral models and therapeutic protocols developed so far for psychological disorders and chronic diseases have proved effective through clinical research.

Objective: This study aimed to determine the effectiveness of teaching cognitive-behavioral techniques on locus of control in hemodialysis patients.

Methods: This controlled clinical trial study was conducted in 2015 with 76 patients selected by census and treated with a hemodialysis machine in the dialysis department of Vali-Asr Hospital in the city of Meshkinshahr. A total of four patients were excluded because of their critical conditions while the rest, who were recruited, were randomly divided into two equal groups of 36 patients as the intervention and control groups. First, the locus of control was measured in both groups through a pretest, and cognitive-behavioral techniques were then taught to the intervention group during eight 45 to 90 -minute sessions. The locus of control in patients of both groups was finally re-measured through a posttest. Data were collected using Rotter's Locus of Control Inventory. The Wilcoxon test and Mann-Whitney U test were respectively used in SPSS18 for data analysis.

Results: In the pretest and posttest stages respectively, $4.8 \%$ and $14.3 \%$ of samples in the control group as well as $14.3 \%$ and $33.3 \%$ of samples in the intervention group enjoyed internal locus of control. The difference between the pretest and posttest scores of internal locus of control in the intervention group was significant $(\mathrm{p}=0.004)$, which indicates the positive effect of cognitive-behavioral psychotherapeutic intervention on internalization of locus of control in this group.

Conclusions: Given the external locus of control in most of the study patients and also the positive significant effect of cognitive-behavioral psychotherapy on internalization of locus of control in this group of patients, it appears necessary to have a psychology resident present in the hemodialysis department to teach the necessary cognitive-behavioral techniques to internalize the locus of control.

Trial registration: The trial was registered at the Thai Clinical Trial Registry (http://www.clinicaltrials.in.th) with the TCTID: TCTR20170707003.

Funding: The authors received no financial support for the research, authorship, and/or publication of this article.

Keywords: Cognitive-behavioral Therapy, Hemodialysis, Locus of control, Meshkinshahr
\end{abstract}

\section{Introduction}

Chronic renal failure, which leads to hemolytic uremic syndrome (HUS) (1), is a process whereby a significant continuous irreversible loss of nephrons, and consequently the kidney's ability to excrete metabolic wastes and

\section{Corresponding author:}

Associate Professor Dr. Esmaeil Farzaneh, Department of Forensic Medicine and Toxicology, Faculty of Medicine, Ardabil University of Medical Sciences, Ardabil, Iran.

Tel: +98.9141521639, Fax: +98.4533522082, Email: dr.farzaneh.milad@gmail.com

Received: December 25, 2016, Accepted: July 17, 2017, Published: October 2017

iThenticate screening: July 19, 2017, English editing: September 21, 2017, Quality control: October 15, 2017

(C) 2017 The Authors. This is an open access article under the terms of the Creative Commons Attribution-NonCommercialNoDerivs License, which permits use and distribution in any medium, provided the original work is properly cited, the use is non-commercial and no modifications or adaptations are made. 
retain fluid-electrolyte balance is lost. End stage renal disease (ESRD) occurs when the kidneys stop functioning properly to sustain one's life without the use of adjuvant or alternative therapies including hemodialysis and peritoneal dialysis. Currently, 1.4 million people worldwide suffer ESRD (2-4). According to the Center for Special Diseases of the Ministry of Health and Medical Education, around 40,000 Iranians suffered chronic renal failure in 2009, with an annual growth of $11 \%$ in Iran (5). Cognitive behavioral training (CBT), which aims to modify incorrect interpretations, creating a sense of control over life, reinforcing constructive coping skills and finally mental health (6), emphasizes that thought processes have a major impact on quality of life (7). According to CBT, beliefs and attitudes should be seriously addressed. CBT experts believe it does not matter what has happened, but it matters how the event is interpreted. Cognitive distortions in people should be considered to approximate with their core beliefs and establish an intimate relationship with them. They should learn how to record their thoughts and feelings; their fundamental beliefs should be shown to them and their relationship with current problems should be clarified; they should then be helped with the gradual elimination and replacement of inefficient beliefs with efficient ones (8). The cognitive aspect of this therapeutic method is to teach methods of coping with stress, and reduce the consequent physiological changes that affect mental health. The behavioral aspect of this method is to help patients control their stress by doing exercises such as progressive relaxation, diaphragmatic breathing, imagery etc., which in turn reduces psychological symptoms in people (9). Many of the cognitive behavioral models and therapeutic protocols developed so far for psychological disorders and chronic diseases have proved effective through clinical research (10). The study conducted by Darvishi on the effects of two cognitive behavioral techniques (relaxation and mental imagery) on anxiety, depression and hope in women with breast cancer demonstrated that the technique causes more relaxation and less anxiety in patients (11). Locus of control in Rotter's learning theory means internal and external locus of control. Individuals with external locus of control believe that their success or failure is managed by external factors such as destiny, chance, strong people and unpredictable environmental forces, while those with internal locus of control attribute their successes and failures to their own actions and capabilities as the determining factor (12). People with an internal orientation are more popular, have higher self-esteem and tend to be more socially competent. Furthermore, they are less likely to experience emotional turbulence and commit delinquencies, and can better deal with stress (13-15). Rotter explained the relationship between internal and external locus of control and psychiatric symptoms in 1975 as individuals who tend to have internal locus of control expose less psychologic symptoms than those with external locus of control (14). Having control over one's life has many benefits including promotion of desirable behaviors, more psychological adjustment and less physical, mental and behavioral problems $(16,17)$. Although hemodialysis delays the mortality caused by chronic renal failure, it significantly reduces Quality of Life rate (18), which causes numerous psychosocial problems as a consequence of the treatment and changes in lifestyle $(19,20)$. These problems are considered a global concern (21). According to studies, most of these patients suffer a low quality of life and performance (22). A study on locus of control, indicates that people who feel capable of affecting their life events, enjoy more behavioral and social health than those lacking such a belief (23). Another investigation showed that people with internal locus of control identified themselves as having more control over life and felt more responsible for directing their life (24). Locus of control is an important variable affecting quality of life (25-29) and also cognitive-behavioral therapy has a great impact on quality of life in hemodialysis patients $(30,31)$. Moreover, Naderi conducted a study on the effectiveness of teaching cognitive behavioral techniques on locus of control in hemodialysis patients.

\section{Material and Methods}

\subsection{Trial design and participants}

This study was a controlled clinical trial that was conducted from September 10, 2015 to June 20, 2016. This controlled clinical trial study was conducted on a statistical population of 76 hemodialysis patients who were selected by census from among patients undergoing hemodialysis in the dialysis department of Vali-Asr Hospital in the city of Meshkinshahr, during the study period. Meshkinshahr is located in Ardebil province in the northwest of Iran. Given the limited number of patients, all 76 patients were enrolled by census method in the study.

\subsection{Selection criteria}

The inclusion criteria for participation in this study were: 1) Having chronic kidney disease, 2) Hospitalization in the hemodialysis department of Vali Asr Hospital in Meshkinshahr, 3) Having favorable conditions for participation in the study, and 4) confirmed satisfaction with participation in the study. The exclusion criteria were dissatisfied patients and patient's inability to participate in the study. A total of four patients were excluded because of their critical conditions, malaise or lack of interest in participation. 


\subsection{Interventions}

Upon admission of both groups to the department, the effects of CBT, study objectives as well as ethical points were explained to them; they were ensured of the confidentiality of the data collected and were told they could withdraw at any time and for any reason if they were unwilling to continue. At the beginning, the locus of control of both groups was measured through a pretest, and cognitive-behavioral techniques were then taught to the intervention group during eight 45 to 90 -minute sessions. Given the physical conditions of patients with chronic kidney disease, a combination of Ellis training packages, Binder's rational emotive therapy model and Donald Mayknbam's model of cognitive behavioral changes were used for training the intervention group. To minimize the effects of confusing variables, we tried to the isolate the two groups so to have nothing to do with each other. Rotter's Locus of Control Inventory, developed by Rotter in 1966, was used in this study to assess the subjects. This inventory consists of 29 pairs of alternatives lettered a or b, has a high validity and reliability and has been used in numerous studies (32-34). There are 29 binomial questions, 23 of which are scored to produce a score between 0 and 23 . Higher scores denote external locus of control.

\subsection{Outcomes}

In the pre-test, the locus of control of patients was measured. Subsequently, cognitive-behavioral psychotherapy was performed on patients and after eight weeks, the patient's locus of control was measured again. Determining the effect of cognitive-behavioral psychotherapy on the locus of control and, consequently, the quality of life of renal patients under hemodialysis is the outcome of this study.

\subsection{Randomization and blinding}

In this controlled clinical trial, 76 patients were randomly divided into control and intervention groups. Randomization was done by one of the researchers who did not have any role in the treatment of the participants.

\subsection{Statistical methods}

The Wilcoxon test and Mann-Whitney U test were respectively used in SPSS18 to analyze the relationship between the pretest and posttest data as well as the data of intervention and control groups.

\subsection{Research ethics}

This study was reviewed at the Ardabil University of Medical Sciences Research Ethics Council and was approved with number "IR.ARUMS.FEC.1394.25". The participation of patients in the study was completely voluntary. Eventually, we obtained written consent from patients for the study.

\section{Results}

Of the 72 participants in the study, 30 patients were female (41.6\%), and 42 were male (58.4\%). The average age of the participants in the control group and intervention group were 58.70 and 49.48 years respectively and the standard deviation was 11 in both groups. The age range in the control group, was 18 to 78 years old and in the intervention group was 18 to 62 years old. In terms of studies, 39 patients (54.16\%) were illiterate, 23 patients (31.94\%) were secondary, seven patients $(9.72 \%)$ were diplomas and three patients $(4.16 \%)$ had Associate Degree. Most of patients $(44.28 \%)$ were housewives. The cause of chronic renal failure in 23 patients $(31.94 \%)$, were high blood pressure, in 21 patients $(29.16 \%)$, were nephrolithiasis, in 16 patients $(22.22 \%)$ were diabetes, and in 12 patients $(16.66 \%)$ were other items such as stroke, colds, and other genetic causes. As seen in Table 1, in the pretest stage, only two patients $(5.56 \%)$ among 36 patients in the control group scored $\leq 9$ for locus of control, while the rest $(94.44 \%)$ scored $\geq 9$, which means that $5.56 \%$ of members of the group had an internal locus of control in the pretest stage, while other members $(94.44 \%)$ had an external locus of control. Similarly, the posttest score of locus of control of three patients $(8.34 \%)$ among 33 patients in this group was equal to nine or less, while the score of the remaining patients $(91.66 \%)$ was greater than 9 , which means that $8.34 \%$ of members had an internal locus of control in this stage, while other members $(91.66 \%)$ had an external locus of control. As seen in Table 1, the pretest score of locus of control of three patients $(8.34 .3 \%)$ among 36 patients in the intervention group was $\leq 9$, while the score of the rest $(91.66 \%)$ was $\geq 9$, which means that $8.34 \%$ of members of the group had an internal locus of control in the pretest stage, while others (91.66\%) had an external locus of control. Similarly, the posttest score of locus of control of nine patients $(27.8 \%)$ was $\leq 9$, while the score of the remaining patients $(72.2 \%)$ was $\geq 9$, which means that $27.8 \%$ of members of the group had an internal locus of control in this stage, while others $(72.2 \%)$ had an external locus of control. The findings indicated that there was no significant difference between the pretest and posttest scores of locus of control in the control group $(\mathrm{p}=0.848)$, and demonstrated a significant difference between the pretest and posttest scores of locus of control in the intervention group $(\mathrm{p}=0.004)$, which indicates the positive effect of the 
intervention based on teaching cognitive behavioral techniques on the internalization of locus of control in hemodialysis patients. The difference between the scores of the control and intervention groups for locus of control in the pretest and posttest stages, indicate that the difference is not significant $(p=0.752)$ in the pretest stage, but it is significant in the posttest stage $(\mathrm{p}=0.000)$. The changes in the score of locus of control in the pretest and posttest stages as a result of cognitive behavioral psychotherapy in the intervention group, indicate a reduction in the mean score and a tendency toward internal locus of control in 27 of 36 patients; the mean score of 6 patients however, increased toward external locus of control and the score of three patients remained constant with no sign of the psychotherapeutic intervention effect.

Table 1. Pretest and posttest scores of locus of control for the control and intervention groups

\begin{tabular}{|c|c|c|c|c|c|}
\hline \multirow[t]{2}{*}{ Group } & \multirow[t]{2}{*}{ Score } & \multicolumn{2}{|l|}{ Pretest } & \multicolumn{2}{|l|}{ Posttest } \\
\hline & & Frequency & Cumulative Percentage & Frequency & Cumulative Percentage \\
\hline \multirow[t]{15}{*}{ Control group } & 8 & 1 & 2.78 & 1 & 2.78 \\
\hline & 9 & 1 & 2.78 & 2 & 5.56 \\
\hline & 10 & 2 & 5.56 & 3 & 8.33 \\
\hline & 11 & 4 & 11.11 & 3 & 8.33 \\
\hline & 12 & 5 & 13.89 & 4 & 11.11 \\
\hline & 13 & 6 & 16.67 & 5 & 13.89 \\
\hline & 14 & 4 & 11.11 & 4 & 11.11 \\
\hline & 15 & 3 & 8.33 & 3 & 8.33 \\
\hline & 16 & 4 & 11.11 & 5 & 13.89 \\
\hline & 17 & 2 & 5.56 & 1 & 2.78 \\
\hline & 18 & 2 & 5.56 & 2 & 5.56 \\
\hline & 19 & 1 & 2.78 & 2 & 5.56 \\
\hline & 20 & 0 & 0.00 & 1 & 2.78 \\
\hline & 21 & 1 & 2.78 & 0 & 0.00 \\
\hline & Total & 36 & 100.00 & 36 & 100.00 \\
\hline \multirow[t]{18}{*}{ Intervention group } & 5 & 0 & 0.00 & 2 & 5.56 \\
\hline & 6 & 1 & 2.78 & 2 & 5.56 \\
\hline & 7 & 0 & 0.00 & 1 & 2.78 \\
\hline & 8 & 1 & 2.78 & 2 & 5.56 \\
\hline & 9 & 1 & 2.78 & 3 & 8.33 \\
\hline & 10 & 2 & 5.56 & 2 & 5.56 \\
\hline & 11 & 4 & 11.11 & 3 & 8.33 \\
\hline & 12 & 3 & 8.33 & 4 & 11.11 \\
\hline & 13 & 5 & 13.89 & 5 & 13.89 \\
\hline & 14 & 4 & 11.11 & 2 & 5.56 \\
\hline & 15 & 3 & 8.33 & 3 & 8.33 \\
\hline & 16 & 4 & 11.11 & 3 & 8.33 \\
\hline & 17 & 3 & 8.33 & & 0.00 \\
\hline & 18 & 2 & 5.56 & 1 & 2.78 \\
\hline & 19 & 1 & 2.78 & 2 & 5.56 \\
\hline & 20 & 0 & 0.00 & 1 & 2.78 \\
\hline & 21 & 2 & 5.56 & 0 & 0.00 \\
\hline & Total & 36 & 100 & 36 & 100 \\
\hline
\end{tabular}

\section{Discussion}

Much research has been conducted on locus of control in different fields, but to the best of our knowledge, no study has been carried out on the effect of teaching cognitive behavioral techniques on locus of control in hemodialysis patients. Our results divulged that a high percentage of hemodialysis patients have external locus of control and the longer the duration of the therapy, the more external their locus of control. Several studies have reported that locus of control is external in hemodialysis patients $(35,36)$. Two reasons seem to be valid for this. First, as hemodialysis patients are completely dependent upon others such as doctors, family, dialysis staff, and machines, so they feel that they have little freedom and authority. Second, having religious and spiritual beliefs is the most common way of 
coping with problems and illness (37). Evidence shows that most human problems are caused by locus of control (38). A study revealed a significant difference in locus of control between students with and without learning disability; students with higher learning disability had an external locus of control, while those without learning disability had more internal locus of control (25). A study illustrated the direct interaction of locus of control with personal adjustment (14), self-esteem and desired discipline such that individuals with internal locus of control enjoyed a favorable behavior more than those with external locus of control (17). These findings somehow confirm the findings of our study. In relation to cognitive-behavioral psychotherapy, our results showed that cognitivebehavioral psychotherapy can meaningfully change the locus of control from the external to the internal in hemodialysis patients. Positive Impact of Cognitive Behavioral Psychotherapy on variables related to quality of life has been reported in numerous studies (39-41). The low level of literacy and the high mean age of patients made it difficult for them to comprehend the concepts of locus of control. The research team therefore made more attempt to minimize the effects of this limitation by trying to explain the concepts and collecting data through face to face interviews. It is recommended that this study be conducted in other fields so the findings can be analyzed and compared.

\section{Conclusions}

This study showed that cognitive-behavioral psychotherapy can meaningfully change the locus of control from the external to the internal in hemodialysis patients, which indicates the importance of paying attention to psychological interventions in these patients. A psychology team appears necessary in every dialysis department for teaching and performing psychotherapy for patients to internalize locus of control. A complementary research on the effect of cognitive-behavioral psychology on other important quality of life variables on hemodialysis patients can be a good route for future research on this topic.

\section{Acknowledgments:}

This study was accomplished in the hemodialysis department of Vali-Asr Hospital in Meshkinshahr. We hereby express our gratitude to all patients who cooperated with us despite their illness as well as the hardworking personnel of the department.

\section{Trial registration:}

The trial was registered at the Thai Clinical Trial Registry (http://www.clinicaltrials.in.th) with the TCTID: TCTR20170707003.

\section{Funding:}

The authors received no financial support for the research, authorship, and/or publication of this article.

\section{Conflict of Interest:}

There is no conflict of interest to be declared.

\section{Authors' contributions:}

All authors contributed to this project and article equally. All authors read and approved the final manuscript.

\section{References:}

1) Royani Z, Rayyani M, Behnampour N, Arab M, Goleij J. The effect of empowerment program on empowerment level and self-care self-efficacy of patients on hemodialysis treatment. Iran J Nurs Midwifery Res. 2013; 18(1): 84-7. PMID: 23983734, PMCID: PMC3748561.

2) Farhadi M, Dadgari F, Farsi Z, Dadgari A. Dialysis adequacy in chronic hemodialysis patients in a military hospital. Ebnesina. 2015; 17(2): 36-42.

3) Institute JB. Self-management of hemodialysis for end stage renal disease. The JBI Database of Best Practice Information Sheets and Technical Reports. 2011; 15(8): 1-4.

4) Oshvandi K, Kavyannejad R, Borzuo R, Gholyaf M, Salavati M. Dialysis adequacy with high flux membrane in hemodialysis patients at shahid beheshti hospital, hamedan. Journal of Urmia Nursing and Midwifery Faculty. 2012; 10(4).

5) Pourebrahimi M, Rahimi A, Tayebi A, Ebrahimi H. The effect of consuming oral Vitamin C on exhaustion of hemodialysis patient caregivers. Iran J Crit Care Nurs. 2013; 6(2): 95-100.

6) Solaz Portolés JJ, Sanjosé López V. Cognitive variables in science problem solving: A review of research. Journal of Physics Teacher Education Online. 2007; 4(2): 25-32. 
7) Cobb B, Sample PL, Alwell M, Johns NR. Cognitive-Behavioral Interventions, Dropout, and Youth With Disabilities A Systematic Review. Remedial and Special Education. 2006; 27(5): 259-75. doi: 10.1177/07419325060270050201.

8) Cerel J, Fristad MA, Verducci J, Weller RA, Weller EB. Childhood bereavement: psychopathology in the 2 years postparental death. J Am Acad Child Adolesc Psychiatry. 2006; 45(6): 681-90. doi: 10.1097/01.chi.0000215327.58799.05. PMID: 16721318.

9) Abolghasemi A, Rahimi A, Abasaliloo SV. Efficacy of Cognitive-Behavioral Stress Management Training on Symptoms Severity and Psychological Well-being of Patients with Irritable Bowel Syndrome. Govaresh. 2015; 20(3): 178-84.

10) Greer S, Moorey S, Baruch J, Watson M, Robertson BM, Mason A, et al. Adjuvant psychological therapy for patients with cancer: a prospective randomised trial. BMJ. 1992; 304(6828): 675-80. doi: 10.1136/bmj.304.6828.675. PMID: 1472184, PMCID: PMC1881503.

11) Alipour A, AliAkbari-Dehkordi M, Sharifi-Saki S. Effectiveness of teaching anger management skills using cognitive-behavioral approach in the reduction of aggression among women suffering from breast cancer. Feyz. 2015; 19(2): 127-34.

12) Williams M, Burden RL. Psycology for language teachers: Ernst Klett Sprachen; 2004.

13) Slavin RE, Davis N. Educational psychology: Theory and practice. 2006.

14) Ghartappeh A, Talepasand S, kajbaf MB, Abolfathi M, Solhi M, Gharatappeh SH. Relationship between personal and social adjustment with locus of control and gender in intelligent high school student. Iran $\mathrm{J}$ Health Educ Health Promot. 2015; 3(2): 159-66.

15) Heydari Tafreshi G. Structural equation modeling approach in explaining the relationship between attachment style and locus of control with marital satisfaction in Islamic Azad University staff of Roudehen. Journal of Educational Management Research. 2012; 3(3): 23-44.

16) Thompson SC, Sobolew-Shubin A, Galbraith ME, Schwankovsky L, Cruzen D. Maintaining perceptions of control: finding perceived control in low-control circumstances. J Pers Soc Psychol. 1993; 64(2): 293. doi: 10.1037/0022-3514.64.2.293. PMID: 8433275.

17) Saffarian M. Investigation the relationship of locus of control, personality traits, self-esteem and religiosity orientation with discipline desired behavior.

18) Beladi SS, Hosaini Nejad K, Zeraati AA. The Evaluation of Dialysis Adequacy by KT/V in Hemodialysis Patients. Jundishapur Scientific Medical Journal. 2012; 11(1): 43-8.

19) Royani Z, Asadi N. Assessing the Relation Between Social Support and Depression among Patients Undergoing Hemodialysis in Kerman City. Hospital. 2015; 4(2): 79-86.

20) Hojat M, Karimyar Jahromi M, Krami Z. Effect of continuous care model on sleep quality and dialysis adequacy of hemodialysis Patients: a clinical trial study. Medical - Surgical Nursing Journal. 2015; 4(1): 31-8.

21) Erdley SD, Gellis ZD, Bogner HA, Kass DS, Green JA, Perkins RM. Problem-solving therapy to improve depression scores among older hemodialysis patients: a pilot randomized trial. Clinical nephrology. 2014; 82(1): 26-33. doi: 10.5414/CN108196.

22) Calia R, Lai C, Aceto P, Luciani M, Camardese G, Lai S, et al. Attachment style predict compliance, quality of life and renal function in adult patients after kidney transplant: preliminary results. Ren fail. 2015; 37(4): 678-80. doi: 10.3109/0886022X.2015.1010989. PMID: 25687387.

23) Krouse N, Show B. Role-specific feelings of control and mortality. Psychol Aging. 2000; 15(4): 617-26. PMID: 11144321.

24) Ashby J, Kottman T, Draper K. Social interest and locus of control: Relationships and implications. Journal of Individual Psychology. 2002; 58(1): 52-61.

25) Alriksson-Schmidt AI, Wallander J, Biasini F. Quality of life and resilience in adolescents with a mobility disability. J Pediatr Psychol. 2005; 32(3): 370-9. doi: 10.1093/jpepsy/js1002. PMID: 16751636.

26) Bartone PT, Hystad SW, Eid J, Brevik JI. Psychological hardiness and coping style as risk/resilience factors for alcohol abuse. Mil Med. 2012; 177(5): 517-24. doi: 10.7205/MILMED-D-11-00200. PMID: 22645877.

27) Ghanbari A, Ghanbari talb M, Bagerian R. A comparative locus of control, cognitive self-consciousness and fear of failure, students with and without learning disabilities. Journal of Learning Disabilities. 2013; 3(1): 148-55.

28) Isganaityte $\mathrm{G}$, Cepukiene $\mathrm{V}$. The relation between resileinec and substance misuse among adolescents in forster care. Specialusis Ugdymas. 2012; 2(27): 35-41. 
29) Jalili Nikoo S, Kharamin SH, Ghasemi Jobaneh R, Mohammad Alippoor Z. Role of Family Resilience and Mindfulness in Addiction Potential of Students. Armaghane-danesh. 2015; 20(4): 357-68.

30) Kusztal M, Trafidło E, Weyde W, Klinger M. Cognitive-behavioral group therapy is an effective treatment for major depression in hemodialysis (HD) patients. Kidney Int. 2010; 77(7): 646-7. doi: 10.1038/ki.2009.530. PMID: 20224588.

31) Anson HM, Byrd MR, Koch EI. Cognitive behavioral treatment to improve adherence to hemodialysis fluid restrictions: a case report. Case Rep Med. 2009; 2009: 835262. doi: 10.1155/2009/835262. PMID: 20069105, PMCID: PMC2801524.

32) Atadokht A, Zare R, Karamati Topraghloo N. The relationship between social interest and general health among elderly non-resident and resident at geriatric centers of Ardabil city. Iranian Journal of Health Education and Health Promotion. 2015; 3(2).

33) Mazlom Bafroi N, Shams Esfand Abad H, Jalali MR, Afkhami Ardakani M, Dadgari A. The relationship between resilience and hardiness in patients with type 2 diabetes in Yazd. J Shahid Sadoughi Univ Med Sci. 2015; 23(2): 1858-65.

34) Torgheh M, Aliakbari dehkordi M, Alipour A. Effect of humour on burnout and resiliency of nurses. J Holist Nurs Midwifery. 2015; 25(76): 57-64.

35) Kohli S, Batra P, Aggarwal HK. Anxiety, locus of control, and coping strategies among end-stage renal disease patients undergoing maintenance hemodialysis. Indian journal of nephrology. 2011; 21(3): 177. doi: 10.4103/0971-4065.83729.

36) Baydogan M, Dag İ. Prediction of Depressiveness by Locus of Control, Learned Resourcefulness and Sociotropy-Autonomy in Hemodialysis Patients. Turk Psikiyatri Derg. 2008; 19(1): 19-28. PMID: 18330740.

37) Hagren B, Pettersen IM, Severinsson E, Lützén K, Clyne N. The haemodialysis machine as a lifeline: experiences of suffering from end - stage renal disease. J Adv Nurs. 2001; 34(2): 196-202. doi: 10.1046/j.1365-2648.2001.01745.x. PMID: 11430281.

38) Cobb-Clark DA, Kassenboehmer SC, Schurer S. Healthy habits: The connection between diet, exercise, and locus of control. Journal of Economic Behavior \& Organization. 2014; 98: 1-28. doi: 10.1016/j.jebo.2013.10.011

39) Rasing SP, Creemers DH, Janssens JM, Scholte RH. Depression and anxiety prevention based on cognitive behavioral therapy for at-risk adolescents: A meta-analytic review. doi: 10.3389/fpsyg.2017.01066.

40) McHugh RK, Votaw VR, Barlow DH, Fitzmaurice GM, Greenfield SF, Weiss RD. Development of an integrated cognitive behavioral therapy for anxiety and opioid use disorder: Study protocol and methods. Contemp Clin Trials. 2017; 60: 105-12. doi: 10.1016/j.cct.2017.07.006. PMID: 28689852, PMCID: PMC5553551.

41) Walter D, Dachs L, Faber M, Goletz H, Goertz-Dorten A, Hautmann C, et al. Effectiveness of outpatient cognitive-behavioral therapy for adolescents under routine care conditions on behavioral and emotional problems rated by parents and patients: an observational study. Eur Child Adolesc Psychiatry. 2017: 1-3. doi: 10.1007/s00787-017-1021-z. PMID: 28685400. 